\title{
ENUNCIACC̃O E PRÁTICAS EDUCATIVAS DIGITAIS: UM ESTUDO DA MULTIPLATAFORMA HORA DO ENEM
}

\section{ENUNCIATION AND DIGITAL EDUCATIONAL PRACTICES: A STUDY OF THE MULTIPLATFORM HORA DO ENEM}

\author{
Naiá Sadi CÂMARA ${ }^{1}$
}

Resumo: O objetivo deste trabalho é apresentar os resultados de um estudo acerca das modificações que as tecnologias de linguagens imprimem nas práticas educativas realizadas em espaços digitais, por meio da análise dos procedimentos enunciativos de instauração da relação sujeito e objetos de aprendizagens em plataformas educativas digitais. Partimos do pressuposto de que essas plataformas configuram práticas educativas predominantemente fundamentadas pelos eixos da dinamicidade, da mistura e da diversidade de gêneros e tipos textuais, pelos hibridismos das práticas escolares e das práticas digitais, e pela convergência midiática e multimodal, em que predomina a modalidade audiovisual. Desse ponto de vista, investigamos a plataforma educativa Hora do Enem com base na proposta teóricometodológica dos Letramentos transmídia. As análises identificaram que a transmidialidade, a mobilidade, as conexões em redes e a ubiquidade afetam a relação dos sujeitos com o processo de ensino e aprendizagem, sobretudo em sua relação tempo/espaço, imprimindo uma autonomia relativa dos percursos de aprendizagens. A práxis enunciativa identificada configura práticas educativas muito semelhantes às práticas educativas formais.

Palavras-chave: Enunciação. Multiplataformas. Práticas educativas. Letramentos transmídia.

\begin{abstract}
This paper aims to present the results of a study about the modifications in educational practices performed in digital spaces due to language technologies by analyzing the enunciative procedures of the establishment of the relationship between subject and learning objects in digital educational platforms. We begin with the assumption that these platforms configure educational practices predominantly based on the axes of dynamics, mixing and diversity of genres and textual types, on the hybridity of school practices and digital practices, and on the media and multimodal convergence in which the audiovisual modality predominates. From this point of view, we investigated the educational platform Hora do Enem, loosely translated as "ENEM (Brazilian High School Examination) Time", based on the theoretical-methodological proposal of transmedia Literacy. The analysis identified that transmidiality, mobility, network connections, and ubiquity affect the subjects' relationship with the teaching and learning process, especially in their time/space relationship, giving a relative autonomy of learning paths. The identified enunciative praxis configures educational practices very similar to formal educational practices.
\end{abstract}

Keywords: Enunciation. Multiplatforms. Educational practices. Transmedia literacies. 


\section{Introdução}

Neste artigo, apresentamos resultados de pesquisas acerca do modo como as mudanças atuais das tecnologias de linguagens, tais como, a convergência midiática, a transmidialidade ${ }^{2}$, a mobilidade, as conexões em rede e a ubiquidade afetam a relação dos sujeitos com o processo de ensino e aprendizagem, por meio da análise dos procedimentos enunciativos da multiplataforma Hora do ENEM.

Com base na proposta teórico-metodológica dos Letramentos transmídia (CÂMARA, 2018), concebida como um modelo transdisciplinar de pesquisa e de ensino e aprendizagem de práticas comunicativas contemporâneas, estabelecemos a articulação entre o conceito de letramentos transmídia e o conceito de práxis enunciativa (FONTANILLE, 2017) e consideramos a prática educativa como uma prática semiótica (FONTANILLE, 2006) - uma semiótica-objeto dotada de um plano de expressão e de um plano de conteúdo, ou seja, uma prática configurada por processos de textualizações.

Por letramento transmídia compreendemos uma prática social convergente, heterogênea, híbrida e polifônica de usos das linguagens, constituída por práticas comunicativas multimodais e hipersemiotizadas de produção e interação complexas entre mídias convergentes.

Com Fontanille (2006, p. 271), adotamos que a práxis enunciativa está “implicada no aparecimento e desaparecimento dos enunciados e das formas semióticas no campo do discurso, ou no acontecimento que constitui o encontro entre o enunciado e a instância que a assume".

Tendo em vista que as práticas enunciativas transmídia operam suas práxis entre coerções da ordem do dado, das memórias socioculturais, da rotina; e as coerções da ordem do novo, das rupturas, do acontecimento, compreender as práticas educativas transmídia dessa perspectiva apresenta-se como uma noção essencial para a compreensão das mútuas implicações entre as operações constituintes da práxis enunciativa formal e informal e suas transmidiações.

Concebemos que os objetos de aprendizagens produzidos e veiculados pela plataforma Hora do ENEM são frutos da prática de tradução transmídia, isto é, da prática

\footnotetext{
2 Com base em Jenkins (2015), trasmidialidade são as práticas de produção e circulação de práticas comunicativas expandidas em diferentes gêneros e tipos textuais em redes de conexões multiplataformas, estruturadas por uma lógica transmídia, compreendida como um processo centrípeto de concentração, difusão, hibridizações, propagações e circulações de conteúdos em redes de conexões transmídia nas quais, cada vez mais, os sujeitos realizam suas práticas sociais
} 
que opera a passagem de um enunciado dado em outro enunciado configurado em outros gêneros e linguagens e veiculado em redes de conexões transmídia convergentes.

Assim, com o objetivo de identificar como se estabelece a relação entre as práticas comunicativas ubíquas e pervasivas e as práticas educativas formal e informal, apresentamos uma análise da plataforma Hora do ENEM e suas expansões, produzida como uma multiplataforma educativa voltada para o ensino médio.

\section{Dos procedimentos metodológicos}

A proposta dos Letramentos transmídia considera a complementariedade, a transversalidade e o hibridismo entre:

a) os diferentes modelos educacionais: formal/informal; tradicional; ensino a distância; ambientes virtuais de aprendizagens; educação ubíqua (SANTAELLA, 2010);

b) as práticas comunicativas transmídia;

c) as práticas de produção e de leitura realizadas no universo da cultura da convergência, participativa e das conexões em redes multiplataformas;

d) a diversidade das práticas sociais contemporâneas dentro e fora dos ambientes digitais e das escolas formais;

e) os níveis de pertinência de análise: os objetos, as práticas, os textos (FONTANILLE, 2006)

Dessa perspectiva, a plataforma será analisada como uma prática comunicativa, cuja eficiência resulta de uma dimensão interpretativa e da integração de estratégias que determinam sua organização aspectual e rítmica, e dos tipos de agenciamentos sintagmáticos que ocorrem de acordo com as isotopias dominantes.

A prática de tradução transmídia, na Hora do ENEM, estabelecerá graus de equivalências entre a obra matriz (gênero científico/escolar) e suas traduções (vídeo aulas, games, animações, documentários, etc.), por processos de triagens e misturas; condensações e expansões, programações e ajustamentos de conteúdos e formas, de

3 Modelo teórico-metodológico dos níveis de pertinência de análise da expressão (signo, textos, objetos, práticas, estratégias e formas de vida) proposto por Fontanille (2014, 2012, 2008a, 2008b, 2005) como níveis que contemplam como os fenômenos culturais apresentam-se no campo de presença dos sujeitos telespectadores (CÃMARA, 2008). 
modo que cada nova produção remeta à obra matriz e ao mesmo tempo apresente conteúdos adicionais.

Em relação ao modo como as mudanças das práticas educativas ubíquas e pervasivas afetam as formas de produção, transmissão e aquisição do saber, consideramos também os níveis dos letramentos transmídia, ou seja, as competências e habilidades de os sujeitos realizarem traduções, curadoria, gestão, produção e recepção de conteúdos, seleção de fontes de informações, transformações de informações em conhecimento, análises, compartilhamentos e disponibilizações com autoria (CÂMARA, 2018).

\section{A plataforma Hora do ENEM}

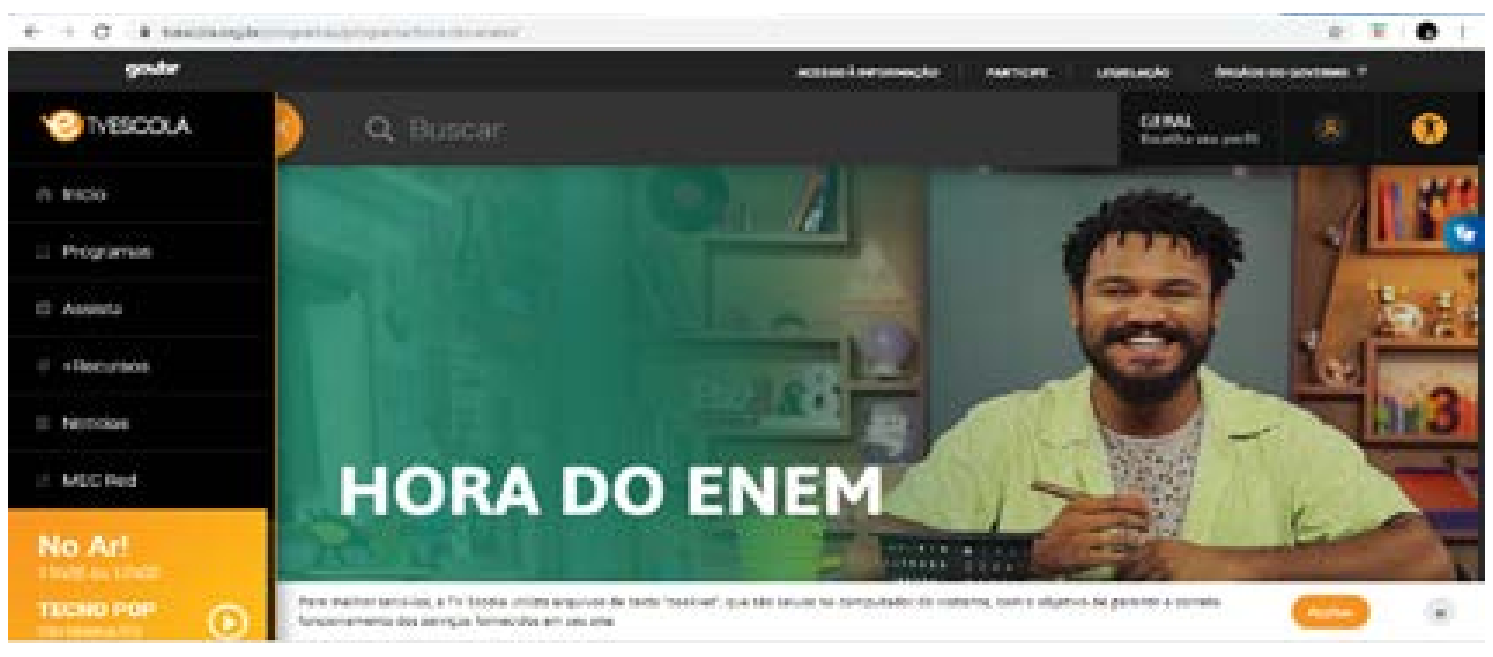

Figura 1. Página do Programa Hora do ENEM

Fonte: https://tvescola.org.br/?s=hora+do+enem

Entendemos por plataforma um espaço digital configurado como uma interface que compreende: uma tecnologia, um serviço e espaços para a cultura participativa ${ }^{4}$. Dessa perspectiva, as plataformas educativas, como espaços de vulgarização didáticopedagógica e de afinidades de aprendizagens ubíquas, configuram suas estratégias enunciativas por meio de práticas de tradução transmídia entre os gêneros científicos/ escolares, os gêneros do entretenimento e os gêneros digitais.

4 Para Nick Srnicek (2017, p. 66), plataformas são aplicações que "provêm uma infraestrutura básica para a mediação entre dois grupos diferentes" e funcionam como intermediários entre agentes diversos: "consumidores, publicidade, prestadores de serviços, produtores, fornecedores, e ainda objetos físicos. 
Hora do ENEM é uma plataforma oferecida pelo MEC (Ministério da Educação) aos sujeitos interessados em adquirir competências para passar no vestibular e assim ingressar em uma faculdade. Foi lançada em 05 de maio de 2016, com a meta de atingir 2,2 milhões de estudantes concluintes do ensino médio das redes pública e privada. Atualmente, pode ser acessada pela plataforma da TV Escola ${ }^{5}$. É configurada como uma estrutura material dotada de uma morfologia, de uma funcionalidade e de uma forma exterior identificáveis, cujo conjunto é destinado a um uso ou a uma prática especializada: a prática educativa.

$\mathrm{Na}$ sua primeira versão, apresentou-se como uma multiplataforma que reunia três plataformas complementares: a Geekie Games ${ }^{6}$, a TV escola e a plataforma Mecflix. ${ }^{7}$ Em 2017, ao acessar o site, encontramos apenas a TV escola. Os links com as duas outras plataformas só são identificados pelo site de busca do Google, onde, após ser digitado "Hora do ENEM", o usuário é direcionado para a plataforma Geekie Games.

Na versão de 2019, as vídeo-aulas da Hora do ENEM podem ser acessadas pelo site da TV Escola. Nessa versão, o Mecflix não está relacionado diretamente ao espaço da Hora do ENEM, apesar de as vídeo-aulas do Geeki Games e do Mecflix serem as mesmas transmídiadas.

Como produto de arquienunciações, a prática enunciativa na Hora do ENEM comporta práticas de tradução transmídia que ocorrem por diferentes processos "[...], atos de enunciação que implicam papéis actanciais, desempenhados, entre outros, pelo próprio texto ou pela imagem, por seu suporte, por elementos do seu ambiente, pelo transeunte, usuário ou observador, tudo o que forma a cena típica de uma prática" (FONTANILLE, 2005, p. 26).

Dessa forma, essa prática enunciativa submete-se às programações dadas pelas coerções do objeto suporte, das práticas concorrentes, da estabilidade e regularidades no tempo e no espaço e aos ajustamentos progressivos, que se estabelecem pela inovação de percursos que procuram a estabilidade no confronto com as coerções já apontadas (FONTANILLE, 2006).

\footnotetext{
5 https://tvescola.org.br/programas/programa/hora-do-enem/

6 https://geekiegames.geekie.com.br/

7 http://mecflix.mec.gov.br/
} 


\section{Das programações, ajustamentos e agenciamentos}

\section{Do objeto suporte}

A plataforma Hora do ENEM organiza-se como um espaço multimodal, híbrido, cuja interface e as modalidades de entradas obedecem aos percursos de interação intuitivos típicos das práticas de interação com a Internet e à curadoria determinada pelos algoritmos. A interface da plataforma cria a comunicação e as condições objetivas que determinam as interações, organiza e facilita o acesso do usuário, além de criar as dimensões para capturar sua atenção para os valores desse objeto.

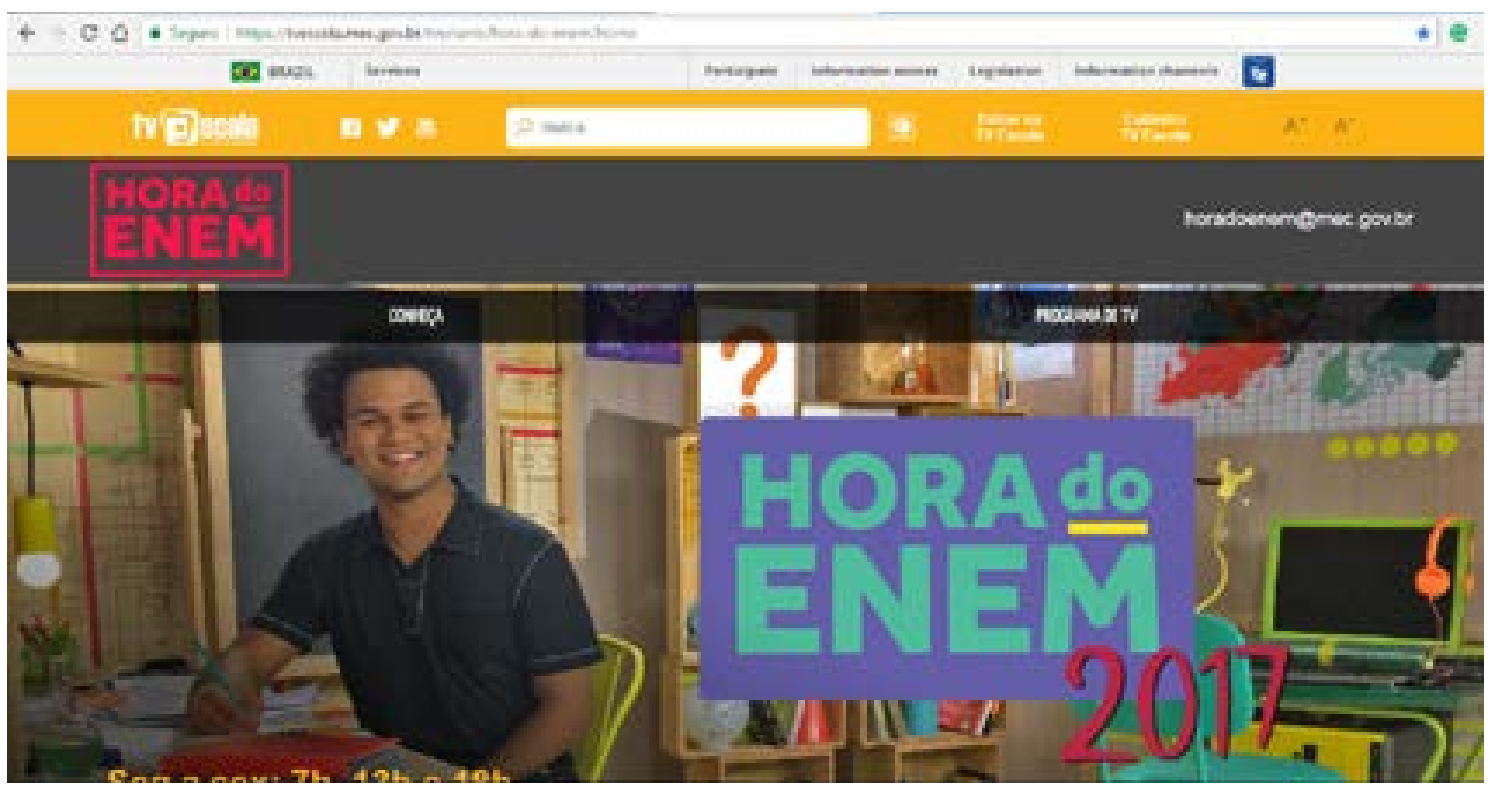

Figura 2. Página do Programa Hora do ENEM

Fonte: https://tvescola.org.br/?s=hora+do+enem

Na parte anterior da plataforma, há a figura do animador, a logomarca da TV escola (produtora dos conteúdos e mídia de base da plataforma), as redes sociais com as quais interage e, ao fundo, o cenário onde as aulas são apresentadas. Na parte inferior, estão os programas ou vídeo aulas, dispostos lado a lado, como em um cardápio, e separados pelas áreas do conhecimento contempladas pelo ENEM. 


\section{O hibridismo das práticas: prática de assistir à TV + prática escolar + prática de interagir na internet}

A práxis enunciativa dessa plataforma configura-se de forma híbrida entre a prática de assistir à TV + prática escolar + prática de jogar+ prática de interagir na internet que são ajustadas a partir de duas tensões:

a) Retrospectiva: (reconhecimento) > início da sequência: memória, crenças $^{8} \mathrm{da}$ origem, que estabelecem as programações e as coerções de práticas concorrentes.

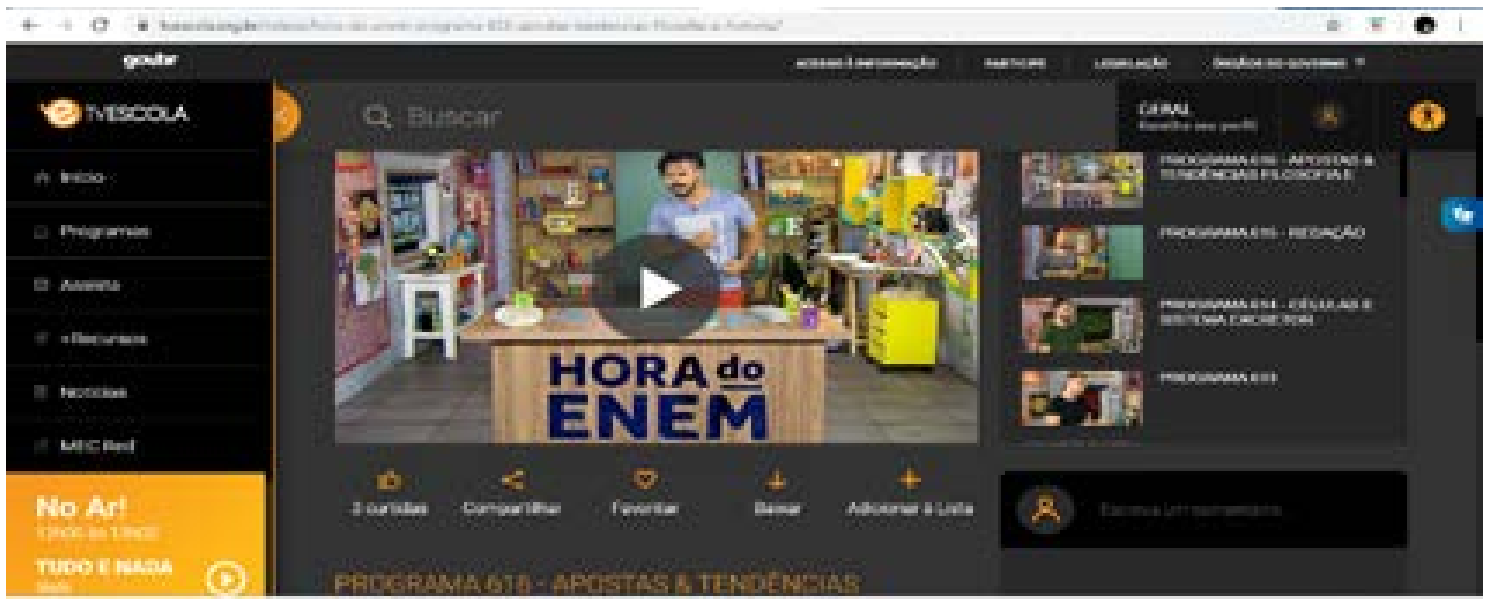

Figura 3. Imagem de uma vídeo-aula

Fonte: https://tvescola.org.br/?s=hora+do+enem

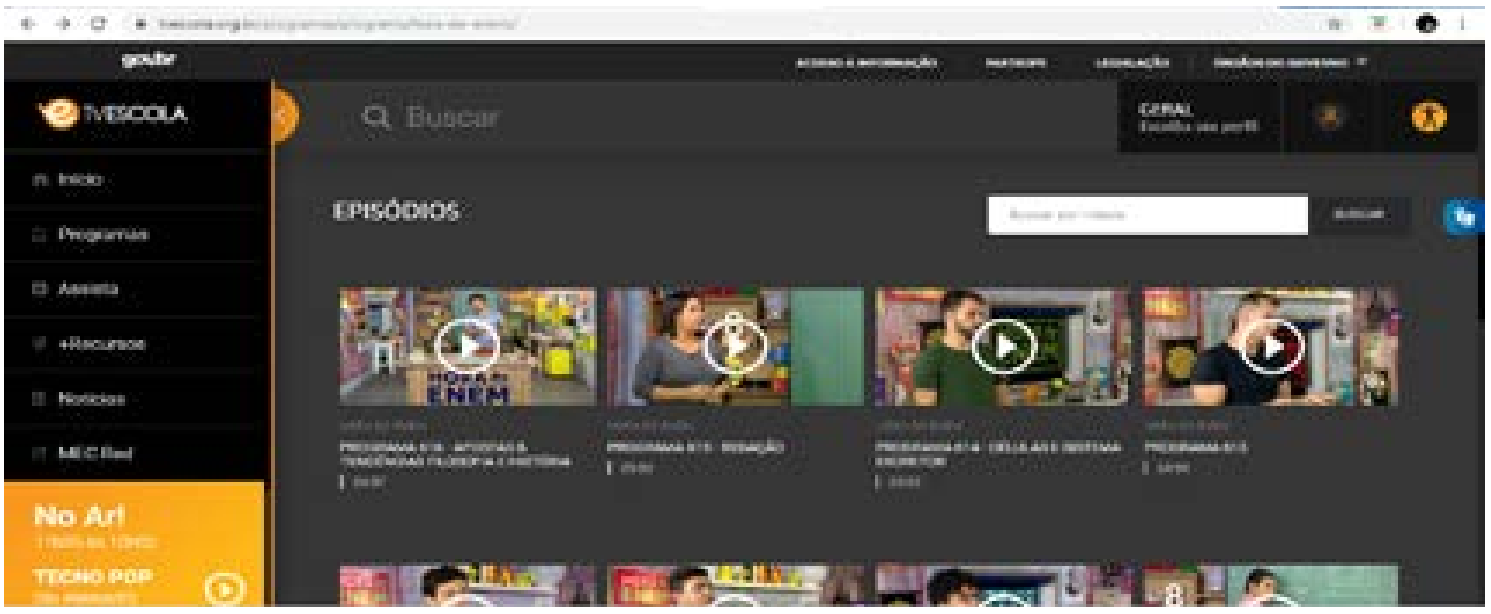

Figura 4. Catálogo das vídeo-aulas

Fonte: https://tvescola.org.br/?s=hora+do+enem

8 Regimes de crenças: condições nas quais uma organização semiótica pode ser interpretada. Crença textual: coerência interna do desenvolvimento narrativo. Crença prática: qualidade de ajustamento das peripécias de um curso de ação aberto nas duas pontas de uma cadeia e submetidos aos acasos da interação com outros cursos de ação, frequentemente imprevisíveis" (FONTANILLE, 2012, p. 59). 
Nas figuras 3 e 4, podemos observar o hibridismo entre TV e Internet: comandos típicos da navegação da internet; protocolos de leitura, formatos e práticas de interações audiovisuais típicos da TV (conteúdos em telas, formatos narrativos seriados, linguagem audiovisual, comandos de acesso); aulas expositivas típicas de cursinhos vestibulares, com ênfase no lúdico.

A prática de assistir à TV com a qual a prática educativa multiplataforma se hibridiza está figurativizada em toda a plataforma, já que a TV escola é a principal produtora dos conteúdos, produzidos em um formato audiovisual seriado. Esses conteúdos são disponibilizados em forma de episódios e catálogos, como em uma prateleira de vídeo locadora, e apresentados no formato de pequenas telas, cujos comandos de interação são os mesmos da TV tradicional.

Há um pré-agendamento das aulas (segunda a sexta, às 7:00, 13:00, 18:00), além da possibilidade de acessar ao vivo a emissora. Como na TV paga, há também a possibilidade de realizar maratonas nos finais de semana, ou seja, assistir a várias horas ininterruptas de diferentes aulas. Além disso, as aulas são denominadas programas - outra característica que também estabelece elo com a prática de assistir à TV - e divididas em episódios.

A hibridização com a prática escolar pode ser identificada, por exemplo, com as aulas expositivas realizadas por professores e com o uso constante de lousas tradicionais manuscritas.

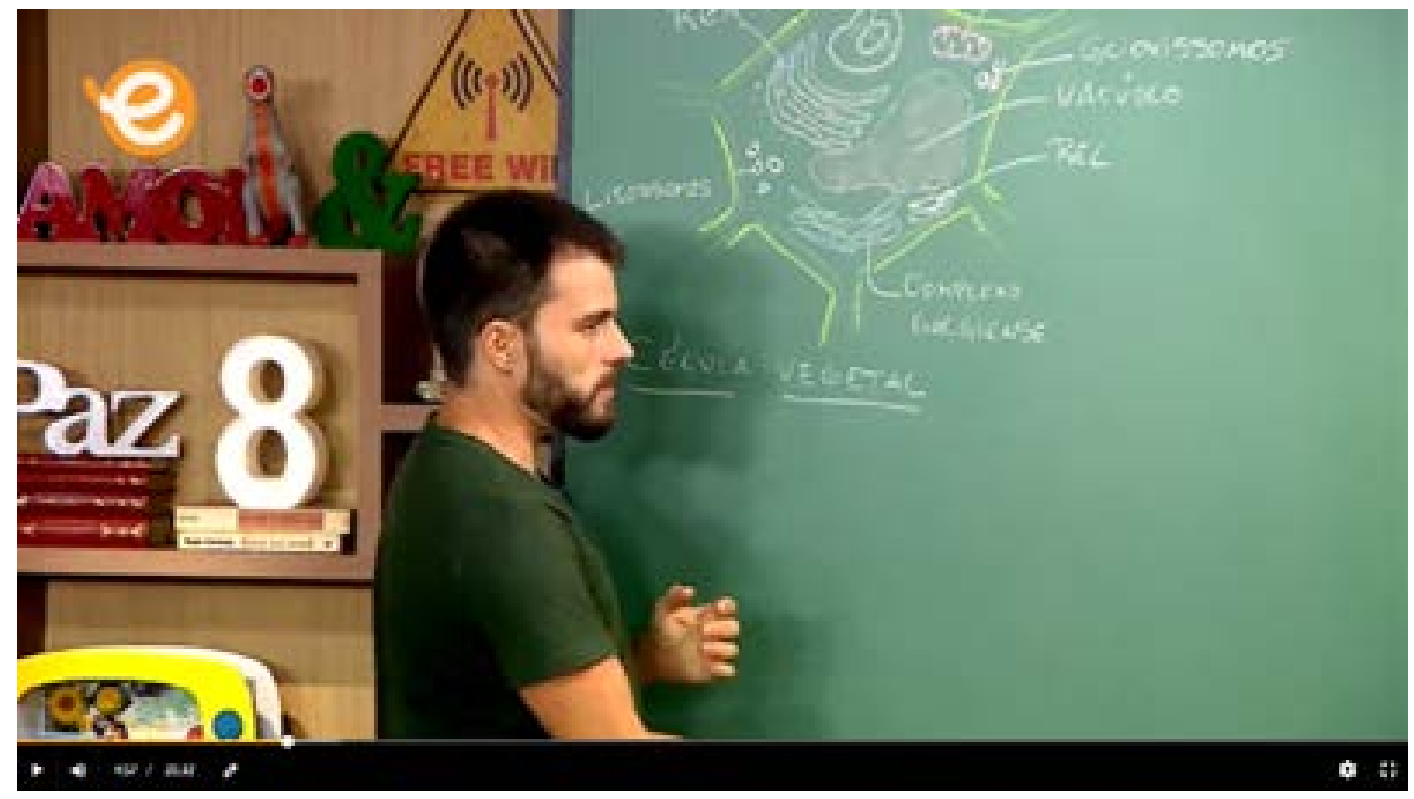

Figura 5. Página do Programa Hora do ENEM

Fonte: https://tvescola.org.br/?s=hora+do+enem 
b) Prospectiva: promessas abertas de novos regimes de crenças e expectativas de leituras: ênfase no lúdico, na diversão e humor; conteúdo adicional (não canônico), gamificação, hibridimos, efeitos especiais, descontração. Os ajustamentos ocorrem entre as práticas enunciativas matrizes - científica/escolar/entretenimento - e as expansões (práticas educativas digitais). Esses arranjos são determinados pela estabilidade e/ou instabilidade no tempo e no espaço que regulam as variações de intensidade, interação, triagens e misturas.

Na plataforma Hora do ENEM e em suas expansões, observamos um investimento em animações conforme a figura 6, ênfase no lúdico; possibilidade de construção da própria videoteca, possibilidade de revisão e a ubiquidade como características inovadoras em relação às práticas escolares formais.

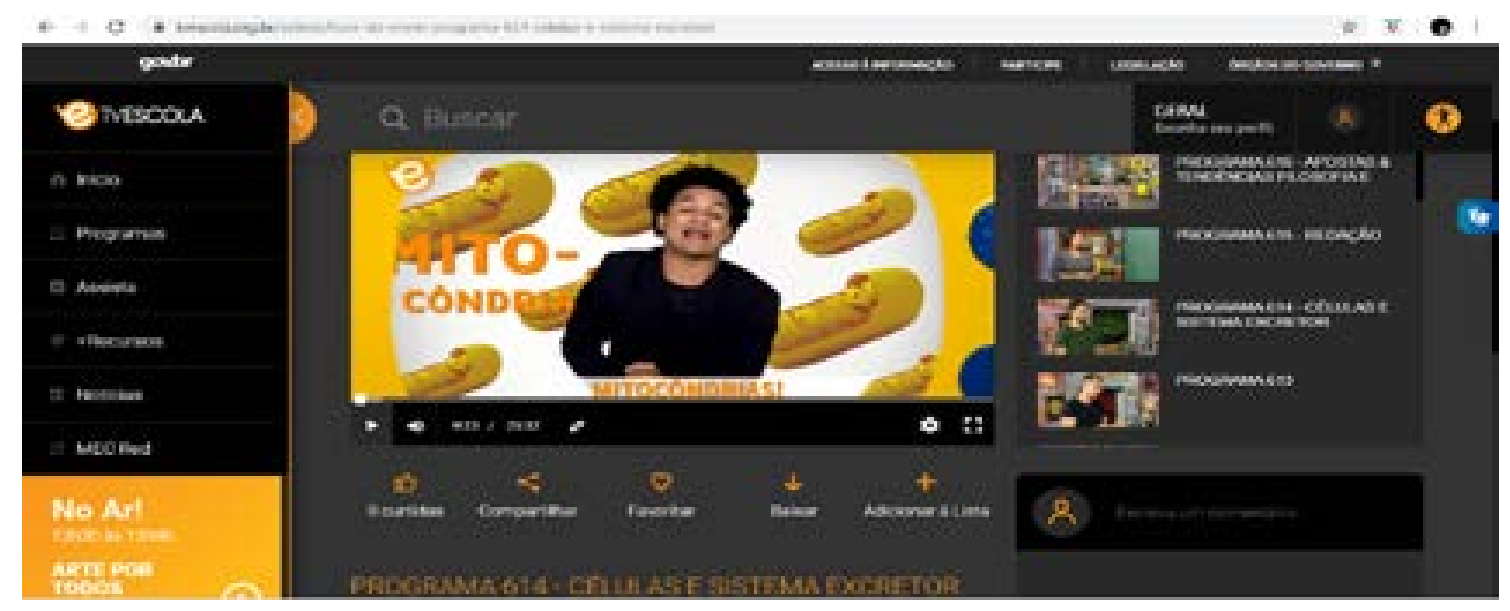

Figura 6. Cena de apresentação de uma vídeo-aula e o uso de animações ao fundo Fonte: https://tvescola.org.br/?s=hora+do+enem

\section{Cenas típicas das práticas educativas transmídia}

\section{Os textos enunciados}

De acordo com Fontanille (1999), os textos organizam-se em tipos textuais que podem ser classificados segundo estes critérios: como longos ou breves, que se relacionam à extensão da unidade de leitura, ao tempo da enunciação, à duração da história ou do acontecimento; como abertos ou fechados que correspondem à relação entre a unidade de leitura e a unidade de edição. Para o autor, a união desses critérios resulta nas seguintes propriedades textuais: a recursividade (se longo e aberto), o desdobramento (se longo e fechado), a fragmentação (se breve e aberto) e a concentração (se breve e fechado). 
Nas plataformas de origem Hora do ENEM e "Mecflix", as vídeo-aulas (programas/ episódios) estão na íntegra, com duração média de 25 minutos (metade da duração de uma aula tradicional), e nas plataformas para onde são transmidiados (Facebook e Twitter), esses textos configuram-se como teasers, memes, bate-papos, isto é, são reduzidos a textos menores, cuja duração gira em torno de 0,50 minutos. Apresentam, portanto, nesses espaços, uma visão fragmentada e lacunar de incompletude, a fim de levar o enunciatário ao vídeo completo na plataforma de origem.

Todas as vídeo-aulas da plataforma organizam-se por uma sequência canônica do tipo: cena lúdica > abertura oficial > aparição do animador > apresentação do professor convidado > aula. Essa sequência didática configura uma estrutura tensiva de aumento da intensidade combinada com o desdobramento da extensão ${ }^{10}$, o que produz uma tensão afetiva e cognitiva: é o esquema da amplificação (FONTANILLE, 2007)"1. Esse esquema revela uma estratégia da práxis enunciativa típica das aulas ministradas nos cursinhos para vestibular tradicionais, cuja ênfase está na dimensão sensível. O aumento da intensidade combinado com o desdobramento da extensão produz uma tensão afetiva e cognitiva.

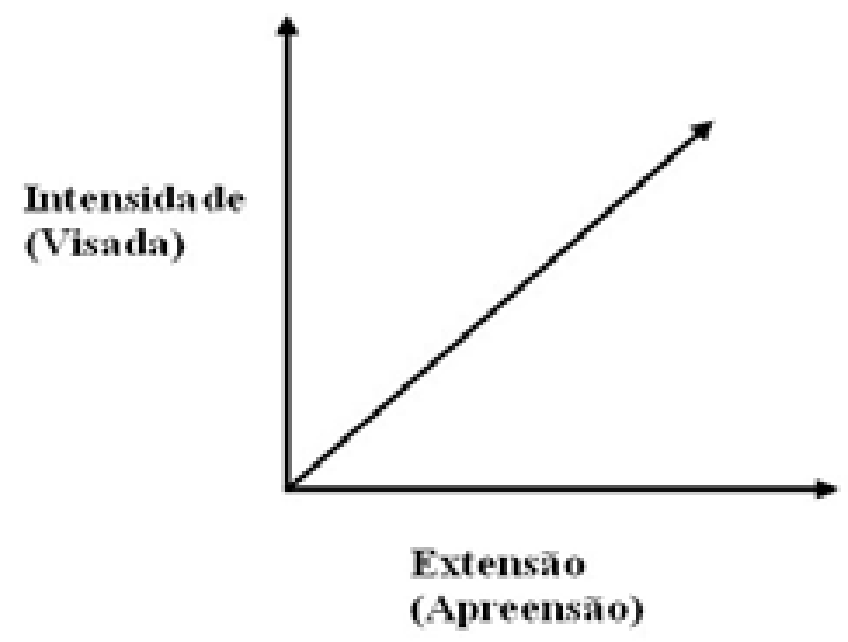

Gráfico 1. Esquema da Amplificação

Fonte: Fontanille (2007, p. 112)

9 Plataforma que recebe as aulas produzidas inicialmente para Hora do ENEM.

10 Eixos que determinam os efeitos de sentidos, e "define $(\mathrm{m})$ um espaço tensivo de recepção e qualificação para as grandezas que têm acesso ao campo de presença" (ZILBERBERG, 2011, p. 67). A intensidade compreende o sensível, os estados de alma; a extensidade é da ordem do inteligível, dos estados das coisas

11 Segundo Fontanille (2007), os esquemas tensivos regulam a interação do sensível com o inteligível: descendente, ascendente, amplificação e atenuação. 


\section{Dimensão topocronológica das cenas predicativas: a dimensão do espaço tridimensional e as propriedades espaço temporais das práticas: ubiquidade/ modelo de transmissão por streaming ${ }^{12}$}

O modelo de transmissão de conteúdos por streaming e a ubiquidade proporcionados pela Internet permitem libertação das grades de programações das práticas educativas formais e imprimem uma autonomia relativa dos percursos de aprendizagem: embora os usuários alunos possam escolher dia, hora, telas e lugares para interagir com o conteúdo disponibilizado pelas plataformas, os cursos de ações permitidos seguem uma pré-determinação pela disponibilização do conteúdo (datas e horas pré-determinados), e conteúdos selecionados segundo os documentos do MEC.

\section{Os regimes de interatividade}

Considerada como uma das principais modificações que as tecnologias digitais de linguagens possibilitam, a interatividade também é fundadora das práticas educativas que se estabelecem, na educação formal, por meio da relação entre professores e alunos.

Elaborada para o processo de ensino e aprendizagem a distância, no qual as interações professor/aluno ocorrem de modo virtual, a estrutura enunciativa dos textos tem que contemplar ao mesmo tempo um fechamento isotópico das temáticas sobre as quais enunciam e prever as possíveis interações que possam surgir por parte dos sujeitos alunos ao longo de cada aula.

Na plataforma Hora do ENEM existe o papel do animador-controle ${ }^{13}$ (FONTANILLE, 2005), pois ele apresenta o tema da aula, suscita as intervenções em cena, faz as transições entre os diferentes tipos de segmentos e opera as debreagens e embreagens internas à emissão de cada programa. Também controla o tempo, exercendo o papel de mediador entre professores e alunos.

Em relação à interatividade, ou seja, ao modo de presença do enunciatário na prática educativa, sua participação ativa não é contemplada na plataforma Hora do ENEM, é fraca no Mecflix e pouco intensa no Facebook e Twitter.

12 Modelo de transmissão de áudio e vídeo por meio de redes, onde é possível assistir a filmes ou escutar músicas de uma maneira mais rápida, uma vez que não é necessário fazer download desse conteúdo.

13 Entre os papéis enunciativos é "aquele de agenciamento interno das diferentes sequencias [...]": sujeitos, isotopias, conteúdos, a "instância da gestão [...]" (FONTANILLE, 2005, p. 137). 
- Enunciação e práticas educativas digitais: um estudo da multiplataforma Hora do ENEM

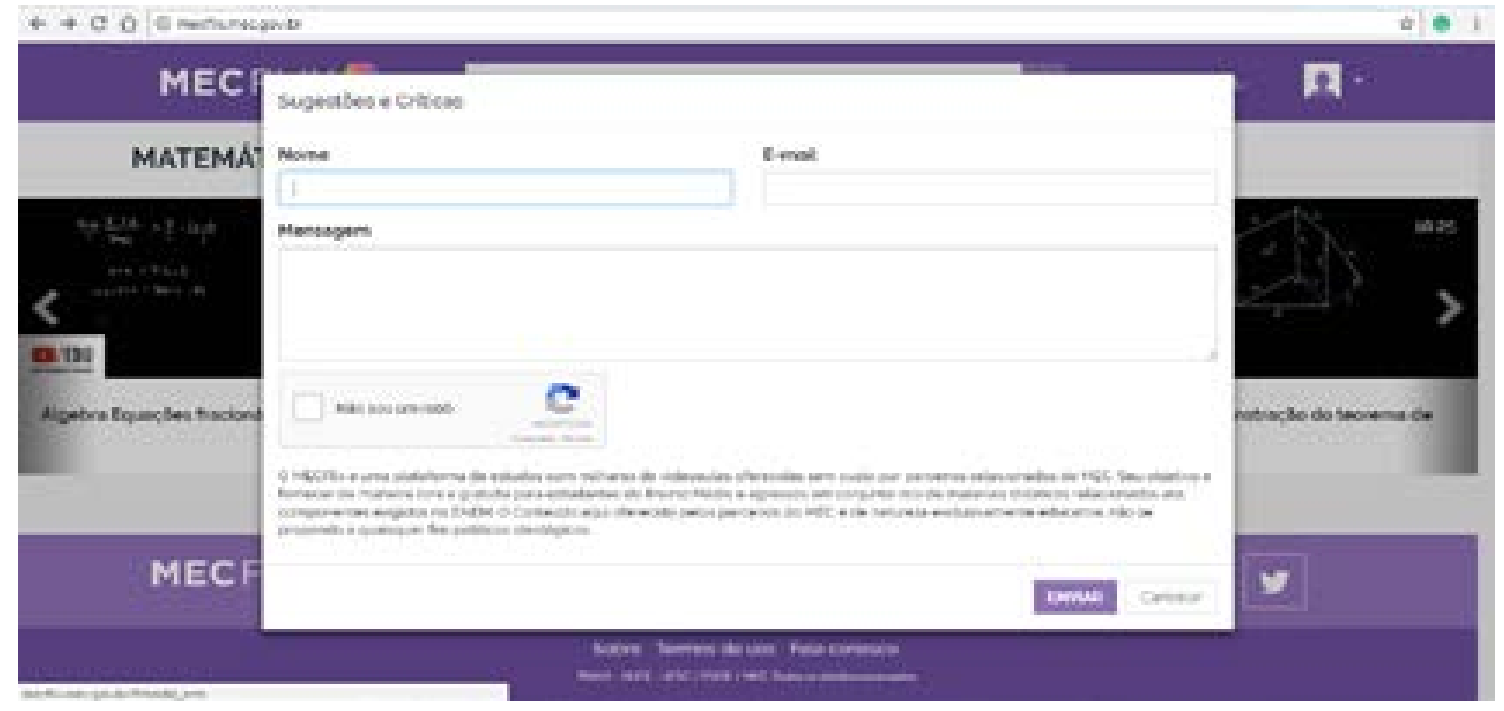

Figura 7. Espaço disponibilizado pela plataforma Mecflix para interação com o usuário

Fonte: http://mecflix.mec.gov.br/

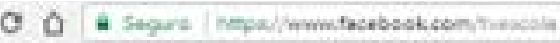

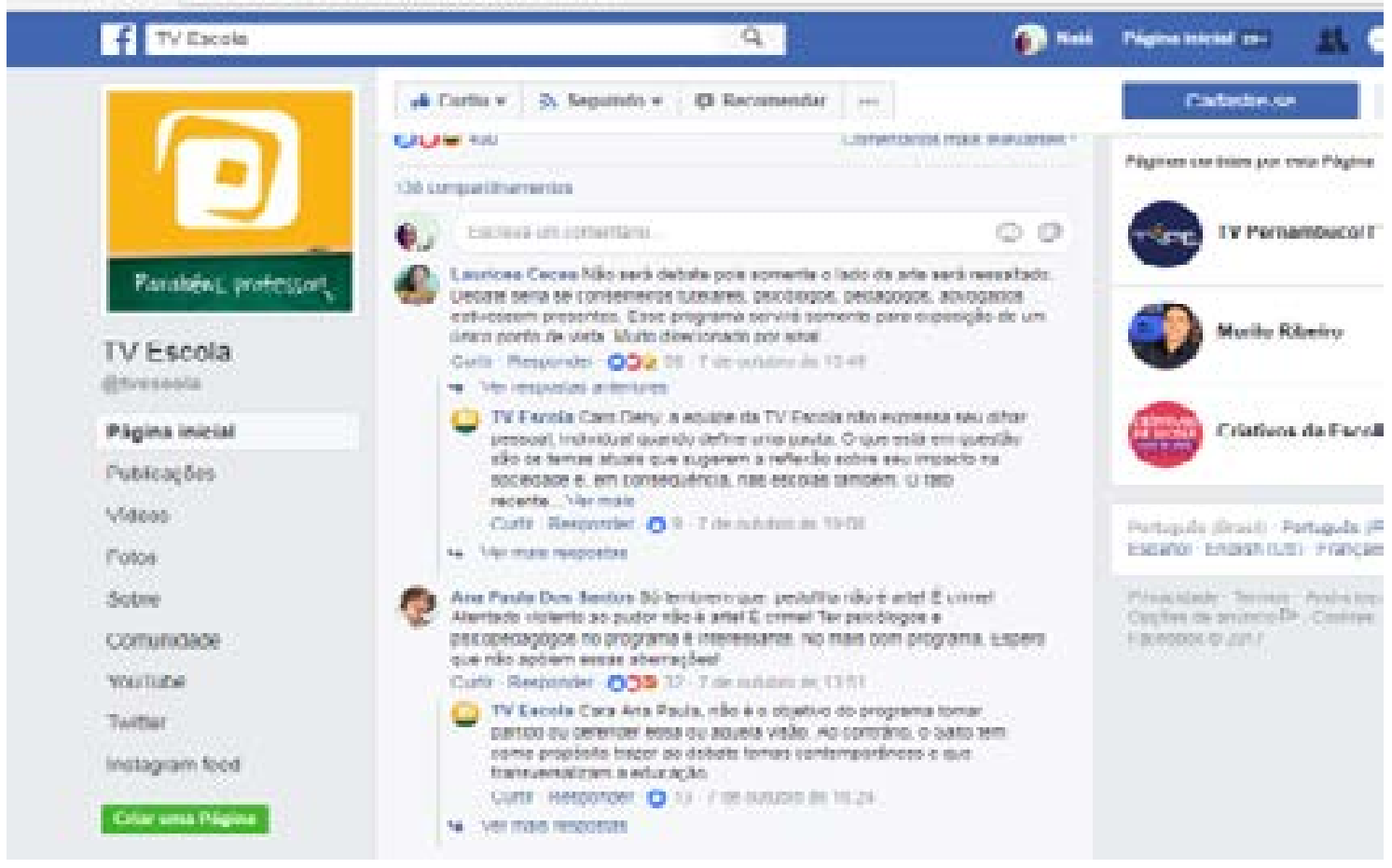

Figura 8. Página TV Escola

Fonte: https://www.facebook.com/tvescola/ 


\section{À guisa de considerações}

Do ponto de vista da relação entre práticas comunicativas ubíquas e pervasivas e práticas educativas contemporâneas, as plataformas analisadas revelam como principais estratégias de interações:

1. Avanços na qualidade de produção que permitem recursos estéticos/ estésicos que promovem de modo imersivo e inclusivo a adesão e o engajamento dos sujeitos às práticas educativas das plataformas.

2. Muito embora as aulas sejam denominadas de programas e sejam apresentadas em um ambiente descontraído e muito diferente de uma sala de aula, elas são "apresentadas/ministradas" por professores das escolas parceiras do projeto, predominantemente de modo expositivo - características típicas das práticas escolares formais de ensino médio.

As tensões entre os ajustamentos e as programações que determinam os graus de abertura e de fechamento das práticas educativas analisadas indicam que a abertura para o exterior é demasiadamente restrita já que as plataformas fecham-se em si mesmas, ou seja, elas organizam seus cursos de forma circular, pois não direcionam o aluno para nenhum outro espaço a não ser os de suas redes sociais (Facebook e Twitter), não apresentam as referências bibliográficas das aulas, nem indicam bibliografias complementares.

Esses dados podem também ser identificados em relação à extensão da unidade de leitura e ao tempo de enunciação (FONTANILLE, 1999) dos tipos textuais, que revelam vídeo-aulas cuja duração e conteúdo são limitados. Essa característica também confirma uma práxis (norma) sociocultural típica do ensino médio, ou seja, muito próxima da estrutura das apostilas, gênero didático pedagógico consagrado na década de 1980 pelos cursos de ensino médio que passam a substituir os livros didáticos: Livro - apostilas - vídeo aulas.

A diversidade das estratégias enunciativas manifestadas na plataforma, apesar de se diferenciarem das práticas formais do ponto de vista sobretudo da multimodalidade e do objeto suporte, aproximam-se das estratégias enunciativas dos cursinhos tradicionais: professores jovens, proximidade com os alunos, aulas com ênfase no sensível, estruturas textuais próximas das apostilas, tom lúdico, conteúdo fragmentado.

A noção de práxis enunciativa permitiu verificarmos que a dinâmica que regula a convocação e a atualização das estratégias enunciativas na plataforma Hora do ENEM organiza-se em torno da reiteração e manutenção das práticas educativas formais. 
Observamos também uma mudança mais significativa em relação à libertação das grades de programações das práticas educativas formais que permitiria uma autonomia em relação aos percursos de aprendizagem, ou seja, permitiria e incentivaria o autodidatismo, a curadoria do sujeito aluno, seu letramento transmídia. No entanto, as estratégias enunciativas na plataforma institucional do MEC revelam que o protagonismo dos sujeitos é relativo apenas à escolha do tempo e do espaço de interação, pois os cursos de ações pré-determinados e os poucos espaços na plataforma para interação e participação dos alunos configuram o controle do Enunciador MEC. Embora a plataforma configure-se em um ambiente dispersivo e assistemático, as práticas educativas propostas pelo MEC procuram manter o controle e a "vigilância " sobre os modos de aprender dos sujeitos alunos.

Do ponto de vista dos letramentos transmídia, as análises revelaram que a interação protagonista esperada de uma plataforma digital não se realiza. A gestão e a curadoria dos conteúdos são restritas, como já apontado neste artigo, e a facilitação das estratégias de ensino e aprendizagem, a proximidade com as práticas de assistir à TV e as práticas escolares formais pouco contribuem para o aprimoramento das práticas letradas dos usuários.

Se há uma tendência de migração das práticas educativas para o ambiente digital da Internet, essas características encontradas na plataforma Hora do ENEM levam-nos a questionar a qualidade das práticas educativas multiplataformas, seu uso e funções, e a pensarmos a relação mídias e educação, pois as modificações que as tecnologias de linguagens imprimiram nas práticas educativas realizadas nesse ambiente digital revelam que a transmidialidade, a mobilidade e as conexões em redes estabelecem práticas educativas que priorizam a superficialidade, a estabilidade, o fechamento nas relações entre os sujeitos e o conhecimento.

\section{Referências}

CÂMARA, N. S. Letramentos transmídia: um conceito e uma metodologia. In: MASSAROLO, J.; SANTAELLA, L.; NESTERIUK, S. (org.). Desafios da transmídia: processos e poéticas. v. 1. São Paulo: Estação das Letras e Cores Editora, 2018. p. 104-129.

FACEBOOK. TV Escola. Disponível em: http://www.facebook.com.br/tvescola. Acesso em: 10 out. 2019. 
FONTANILLE, J. Práxis e enunciação: Greimas herdeiro de Saussure. Tradução Raíssa Medici de Oliveira e Renata Cristina Duarte. Gragoatá, [S.I.], v. 22, n. 44, p. 986-1004, dez. 2017. Disponível em: http://www.gragoata.uff.br/index.php/gragoata/article/view/968. Acesso em: 30 jul. 2019.

FONTANILLE, J. Médias, regimes de croyance et formes de vie. In: OLIVEIRA, A. C. (ed.). Interações sensíveis. São Paulo: Estação das Letras e Cores, 2012. p. 131-148.

FONTANILLE, J. Semiótica do discurso. Tradução Jean Cristtus Portela. São Paulo: Contexto, 2007.

FONTANILLE, J. Pratiques sémiotiques: immanence et pertinence, efficience et optimisation. Nouveaux Actes Sémiotiques. Limoges: Pulim, 2006. p. 107-108.

FONTANILLE, J. Significação e visualidade: exercícios práticos. Porto Alegre: Sulina, 2005.

FONTANILLE, J. Le genre. In: Sémiotique et littérature. Essais de méthode. Paris: PUF, 1999, p. 159-187.

JENKINS, H. Cultura da convergência. São Paulo: Aleph, 2015.

MECFLIX. A plataforma de vídeoaulas gratuitas e sob demanda do MEC. Disponível em: http://mecflix.mec.gov.br/. Acesso em: 10 out. 2019.

SANTAELLA, L. A aprendizagem ubíqua substitui a educação formal. Revista de Computação e Tecnologia da PUC-SP (ReCet), v. 2, n. 1, p. 17-22, 2010.

SRNICEK, N. Platform capitalism. Cambridge: Polity Press, 2017.

TVESCOLA. Hora do ENEM. Disponível em: https://tvescola.org.br/programas/ programa/hora-do-enem. Acesso em: 20 jul. 2019.

ZILBERBERG, C. Elementos de Semiótica Tensiva. Tradução Ivã Carlos Lopes, Luiz Tatit e Waldir Beividas. São Paulo: Ateliê Editorial, 2011. 
- Enunciação e práticas educativas digitais: um estudo da multiplataforma Hora do ENEM

COMO CITAR ESTE ARTIGO: CÂMARA, Naiá Sadi. Enunciação e práticas educativas digitais: um estudo da multiplataforma Hora do ENEM. Revista do GEL, v. 16, n. 3, p. 191-206, 2019. Disponível em: https://revistadogel.gel.org.br/

DOI: http://dx.doi.org/10.21165/gel.v16i3.2786

Submetido em: 02/11/2019 | Aceito em: 02/01/2019. 